\title{
JTRESDA
}

Journal homepage: https://jtresda.ub.ac.id/index.php/jtresda/index e-ISSN : 0000-0000

\section{Studi Penerapan Manajemen Aset Irigasi pada Daerah Irigasi Nglirip Kabupaten Tuban}

\author{
Decka Emeraldi Kurniawan $^{1 *}$, Tri Budi Prayogo ${ }^{1}$, Sri \\ Wahyuni $^{1}$ \\ ${ }^{1}$ Jurusan Teknik Pengairan, Fakultas Teknik, Universitas Brawijaya, \\ Jalan M.T. Haryono. 167, Malang, 65145, INDONESIA \\ *Korespondensi Email: deckakurniawan@gmail.com
}

\begin{abstract}
Irrigation asset management is required as management for irrigation assets to maintain the value of the asset's function and condition. The purpose of this study was to determine the priority of rehabilitated assets. As obtained from the results of the inventory survey, the number of damages in the Nglirip Irrigation Area is 39 points. Physical condition assessment is carried out based on the guidelines of the Ministry of PUPR. Based on the calculation, the main building value is $85,08 \%$ (Good), carrier channel is $76,99 \%$ (Medium), the complementary building is $80,99 \%$ (Medium), Right Nglirip Primary Channel is 81,14 (Good) and Left Nglirip Primary Channel is $79,57 \%$ (Medium). The priority scale is calculated by sorting the smallest physical condition values and the AHP method. The order of priority scale based on the physical condition assessment is the carrier channel, Left Nglirip Primary Channel, complementary structure, Right Nglirip Primary Channel and the main structure. The order of priority scale using the AHP method based on alternatives, the first order is the Right Nglirip Primary Channel, then the Left Nglirip Primary Channel. Meanwhile, based on the criteria, the first order is the carrier channel, then the complementary structure and the main structure.
\end{abstract}

Keywords: analytical hierarchy process, irrigation aset management, priority scale

Abstrak: Manajemen aset irigasi dibutuhkan untuk mempertahankan kondisi dan fungsi dari aset irigasi. Tujuan penelitian ini adalah mengetahui prioritas aset yang direhabilitasi. Didapatkan dari hasil survei inventarisasi, jumlah kerusakan yang ada pada Daerah Irigasi Nglirip berjumlah 39 titik. Untuk penilaian kondisi fisik dilakukan berdasarkan pedoman Kementerian PUPR. Berdasarkan perhitungan didapatkan nilai bangunan utama 85,08\% (Baik), saluran pembawa 76,99\% (Sedang), bangunan pelengkap 80,99\% (Sedang), Saluran Primer Nglirip Kanan 81,14 (Baik) dan Saluran Primer Nglirip Kiri 79,57\% (Sedang). Untuk skala prioritas dihitung dengan cara mengurutkan nilai kondisi fisik terkecil dan metode AHP. Urutan skala prioritas berdasarkan penilaian kondisi fisik adalah saluran pembawa, Saluran Primer Nglirip Kiri, bangunan pelengkap, Saluran Primer Nglirip Kanan dan bangunan utama. Urutan skala prioritas 
menggunakan metode AHP berdasarkan alternatif, urutan pertama adalah Saluran Primer Nglirip Kanan, selanjutnya Saluran Primer Nglirip Kiri. Sedangkan berdasarkan kriteria, urutan pertama adalah saluran pembawa, selanjutnya bangunan pelengkap dan bangunan utama.

Kata kunci: analytical hierarchy process, manajemen aset irigasi, skala prioritas

\section{Pendahuluan}

Indonesia adalah negara yang sebagian besar penduduknya hidup dari hasil pertanian, seperti beras, sagu dan ubi sebagai makanan pokoknya. Jumlah penduduk Indonesia terus meningkat pada tiap tahunnya. Hal ini dapat dilihat pada tahun 2010 penduduk Indonesia berjumlah 238.518.000 jiwa, sedangkan pada tahun 2018 berjumlah 265.015.000 jiwa [1] Pada tahun 2020 penduduk Indonesia diproyeksikan akan berjumlah 271.066.000 [2] Pertumbuhan penduduk akan selalu berbanding lurus dengan meningkatnya kebutuhan pangan. Salah satu cara untuk menjaga ketersediaan kebutuhan pangan untuk penduduk Indoneisa adalah dengan meningkatkan hasil pertanian.

Ada beberapa cara untuk meningkatkan hasil pertanian, antara lain adalah intensifikasi dan ekstensifikasi. Intensifikasi merupakan peningkatan produktivitas lahan pertanian yang sudah ada, sedangkan ekstensifikasi merupakan peningkatan produktivitas lahan dengan cara memperluas wilayah lahan pertanian. Usaha meningkatkan hasil pertanian dengan cara ekstensifikasi dirasa tidak relevan. Karena semakin banyak penduduk, maka semakin tinggi pula kebutuhan wilayah untuk tempat tinggal, sehingga semakin sedikit wilayah yang dapat didayagunakan unutk kebutuhan pertanian. Oleh karena itu, usaha yang efektif untuk meningkatkan hasil pertanian dalam rangka menjaga ketersediaan pangan adalah cara intensifikasi. Salah satu cara intensifikasi yaitu dengan pengelolaan aset irigasi yang baik [3].

Pemerintah melalui Peraturan Menteri Pekerjaan Umum nomor 23 tahun 2015 menyatakan bahwa dalam rangka pengelolaan jaringan irigasi secara efektif, efisien dan berkelanjutan serta guna meningkatkan hasil pertanian dalam rangka ketahanan pangan nasional, maka perlu dilakukan manajemen aset irigasi [4]. Ruang lingkup dalam manajemen aset irigasi yaitu inventarisasi, penilaian kondisi fungsi dan aset dan penetapan urutan skala prioritas [1].

\section{Bahan dan Metode}

\subsection{Bahan}

Secara administrasi Daerah Irigasi Nglirip berada di Desa Mulyoagung, Kecamatan Singgahan, Kabupaten Tuban. Daerah Irigasi Nglirip Kabupaten Tuban mencakup wilayah seluas 1292 Ha. Pembagian wilayah irigasi dibagi menjadi 2 wilayah yaitu primer kanan seluas 798 Ha dan primer kiri seluas 494 Ha. Dam Nglirip adalah bangunan utama yang membendung Kali Guwoterus untuk irigasi di Daerah Irigasi Nglirip Kabupaten Tuban. Pada saluran kanan memiliki panjang total $5732 \mathrm{~m}$ dan saluran kiri sepanjang $5274 \mathrm{~m}$. Menurut wilayah kerja, pengelolaan irigasinya menjadi wewenang dan tanggung jawab 
Pemerintah Provinsi melalui Dinas Pekerjaan Umum Pengairan Propinsi Jawa Timur, UPT PSDA Bengawan Solo di Bojonegoro. [5]

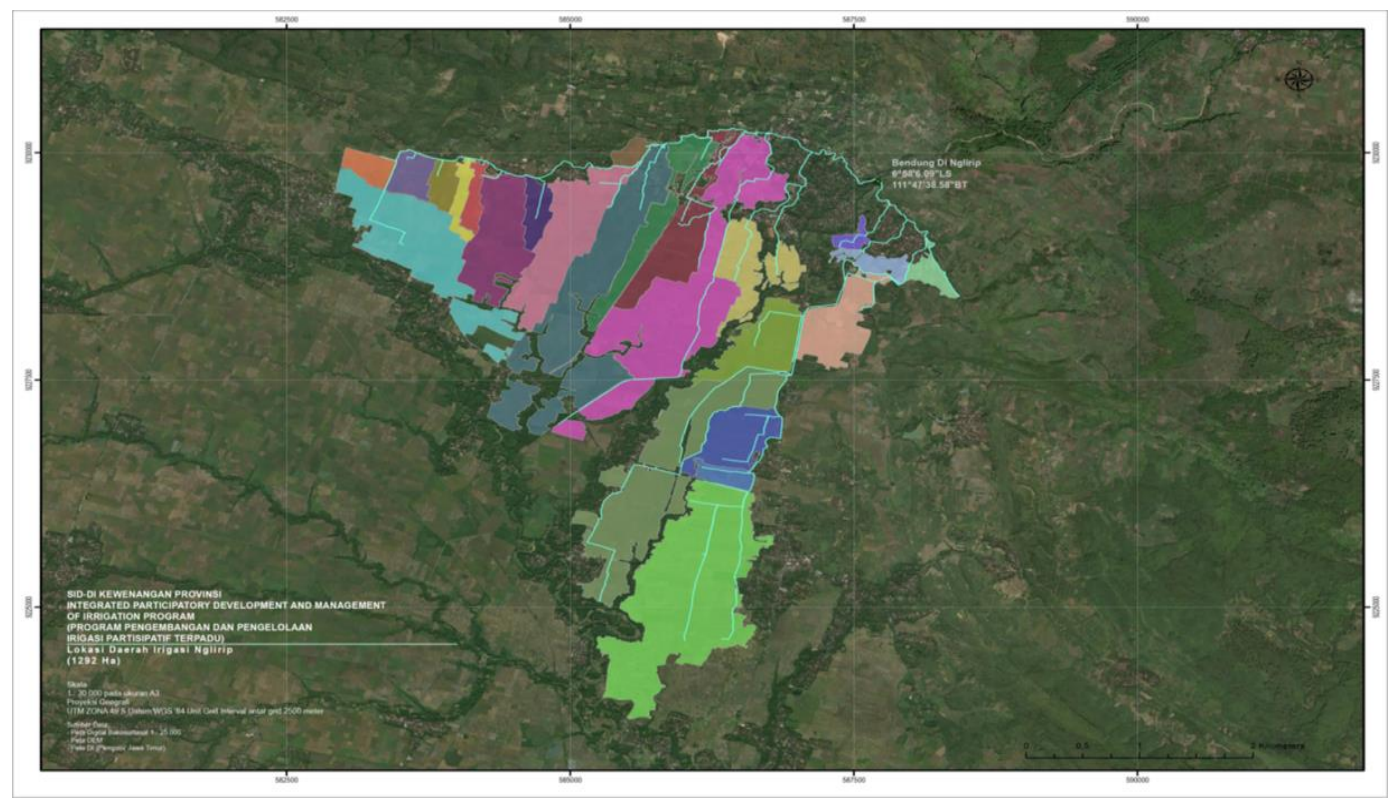

Gambar 1: Peta Daerah Irigasi Nglirip Kabupaten Tuban

Studi ini membutuhkan data-data yang mendukung dalam pengerjaan. Data yang dimaksud adalah data primer dan data sekunder. Data primer yaitu sebuah data hasil pengamatan langsung di lapangan meliputi data bangunan utama, saluran pembawa, bangunan pengatur pada saluran pembawa, bangunan pengukur debit pada saluran pembawa dan bangunan pelengkap pada saluran pembawa [6]. Data sekunder merupakan data-data dari suatu lembaga atau instansi terkait dan juga dari kutipan sumber yang sebenarnya dapat dipertanggung jawabkan. Dimana data ini meliputi data inventarisasi, skema jaringan irigasi, peta-peta dan dokumentasi lapangan [7].

\subsection{Metode}

Indeks kinerja sistem irigasi yang dibahas dalam studi ini hanya indeks prasarana fisik dikarenakan memiliki bobot paling besar. Penilaian kondisi prasarana fisik meliputi bangunan utama, saluran pembawa, bangunan pengatur pada saluran pembawa, bangunan pengukur debit pada saluran pembawa dan bangunan pelengkap pada saluran pembawa [8] Penilaian kondisi prasarana fisik berdasarkan Kriteria dan Bobot Penilaian Kinerja Irigasi Kementerian Pekerjaan Umum dan Perumahan Rakyat tahun 2018. Hal pertama yang dilakukan adalah mengumpulkan data inventarisasi.

Data inventarisasi berfungsi untuk mengidentifikasi aset irigasi yang meliputi kondisi bangunan dan kondisi saluran yang berada di seluruh saluran primer dan sekunder. Untuk mendapatkan data pada suatu aset, maka dibutuhkan data inventarisasi berupa tipe bangunan, kondisi dan fungsi aset serta dokumentasi [9]. Setelah aset irigasi diketahui kondisi dan fungsinya, maka langkah selanjutnya adalah menentukan skala prioritas rehabilitasi. 
Skala prioritas didapatkan dengan cara mengurutkan dari nilai kondisi prasarana fisik berdasarkan Kriteria dan Bobot Penilaian Kinerja Irigasi Kementrian Pekerjaan Umum dan Perumahan Rakyat tahun 2018 yang terkecil dan menggunakan metode AHP. Menghitung dengan metode AHP langkah pertama yaitu membuat struktur hirarki yang dapat dilihat $\mathrm{di}$ Gambar 2. Kemudian mengisi nilai bobot kepentingan untuk masing-masing kriteria dan alternatif. Nilai bobot kepentingan dapat dilihat di Tabel 1. Setelah itu, menghitung matriks perbandingan berpasangan. Hasil matriks perbandingan berpasangan digunakan untuk menghitung vektor prioritas dan nilai CR (Consistency Ratio) sehingga didapatkan urutan skala prioritas [10].

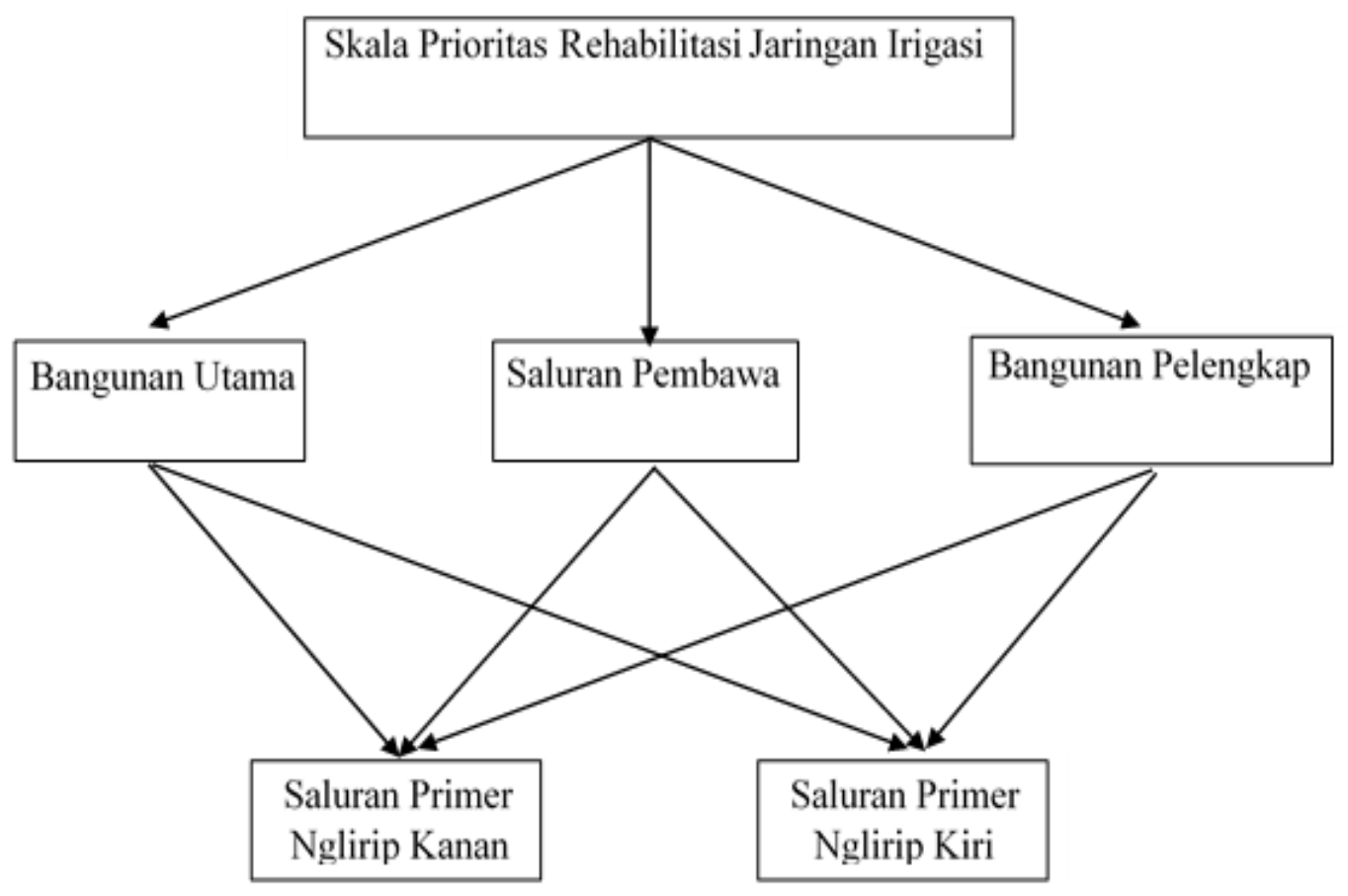

Gambar 2: Struktur Hirarki Metode AHP

Tabel 1: Nilai Bobot Kepentingan Metode AHP

\begin{tabular}{cll}
\hline Bobot & \multicolumn{1}{c}{ Definisi } & \multicolumn{1}{c}{ Uraian } \\
\hline \hline 1 & Sama penting & Kedua elemen mempunyai pengaruh yang sama \\
3 & Sedikit lebih penting & $\begin{array}{l}\text { Pengalaman dan penilaian sangat memihak satu } \\
\text { elemen dibandingkan pasangannya } \\
\text { Satu elemen sangat disukai dan secara praktis } \\
\text { dominasinya sangat nyata, dibandingkan dengan } \\
\text { elemen pasangannya }\end{array}$ \\
7 & Lebih penting & $\begin{array}{l}\text { Satu elemen mutlak lebih disukai dibandingkan } \\
\text { pasangannya, pada tingkat keyakinan tertinggi }\end{array}$ \\
Kebalikan & $\begin{array}{l}\text { Jika elemen } i \text { memiliki salah satu angka diatas ketika dibandingkan } \\
\text { elemen } j \text { maka } j \text { memiliki nilai kebalikannya }\end{array}$ \\
\hline
\end{tabular}




\section{Hasil dan Pembahasan}

Hasil inventarisasi aset irigasi pada Daerah Irigasi Nglirip Kabupaten Tuban yaitu pada saluran primer Nglirip Kanan sepanjang 5732 m yang dibagi menjadi 15 ruas dan saluran primer Nglirip Kiri sepanjang 5329 m yang dibagi menjadi 9 ruas. Pada bangunan irigasi dengan jenis bangunan utama (bendung) sejumlah 1, bangunan sadap sejumlah 24, bangunan ukur sejumlah 2 dan bangunan pelengkap sejumlah 68. Didapatkan dari hasil survei inventarisasi, jumlah kerusakan yang ada pada Daerah Irigasi Nglirip berjumlah 39 titik. Titik kerusakan terbanyak terdapat di Saluran Pimer Nglirip Kanan sebanyak 28 titik. Sementara, untuk ruas yang paling banyak terjadi titik kerusakan adalah Saluran Primer Nglirip Kanan ruas 5 berjumlah 6 titik. Bentuk kerusakan yang terjadi berupa lining saluran yang rusak, saluran tertutup sedimen dan vegetasi serta beberapa bangunan yang tidak berfungsi. Hasil perhitungan penilaian kondisi fisik aset irigasi di Daerah Irigasi Nglirip Kabupaten Tuban dapat dilihat pada Tabel 2.

Tabel 2: Hasil Penilaian Kondisi Fisik

\begin{tabular}{lcc}
\hline \multicolumn{1}{c}{ Aset Irigasi } & Nilai & Kondisi \\
\hline \hline Bangunan Utama & $85,08 \%$ & Baik \\
Saluran Pembawa (Saluran Primer Nglirip Kanan) & $77,00 \%$ & Sedang \\
Saluran Pembawa (Saluran Primer Nglirip Kiri) & $76,98 \%$ & Sedang \\
Bangunan Pelengkap (Saluran Primer Nglirip Kanan) & $83,33 \%$ & Baik \\
Bangunan Pelengkap (Saluran Primer Nglirip Kanan) & 78,66 & Sedang \\
\hline
\end{tabular}

Berdasarkan hasil nilai tersebut, selanjutnya melakukan penilaian kondisi gabungan yang berfungsi untuk mengetahui nilai gabungan dari masing-masing kriteria bangunan [9]. Hasil penilaian gabungan dapat dilihat pada Tabel 3.

Tabel 3: Hasil Penilaian Gabungan

\begin{tabular}{lcc}
\hline \multicolumn{1}{c}{ Aset Irigasi } & Nilai & Kondisi \\
\hline Bangunan Utama & $85,08 \%$ & Baik \\
Saluran Pembawa & $76,99 \%$ & Sedang \\
Bangunan Pelengkap & $80,99 \%$ & Baik \\
Saluran Primer Nglirip Kanan & $81,14 \%$ & Baik \\
Saluran Primer Nglirip Kiri & $79,57 \%$ & Sedang \\
\hline
\end{tabular}

Urutan skala prioritas berdasarkan penilaian kondisi fisik (Tabel 3) yaitu saluran pembawa (nilai kondisi 76,99\%), Saluran Primer Nglirip Kiri (nilai kondisi 79,57\%), bangunan pelengkap (nilai kondisi 80,99\%), Saluran Primer Nglirip Kanan (nilai kondisi $81,14 \%$ ) dan bangunan utama (nilai kondisi 85,08\%).

Setelah mendapatkan urutan skala prioritas berdasarkan penilaian kondisi fisik, kemudian menghitung skala prioritas dengan metode AHP. Nilai perbandingan matriks berpasangan antar kriteria dapat dilihat pada Gambar 3 dan Tabel 4. 


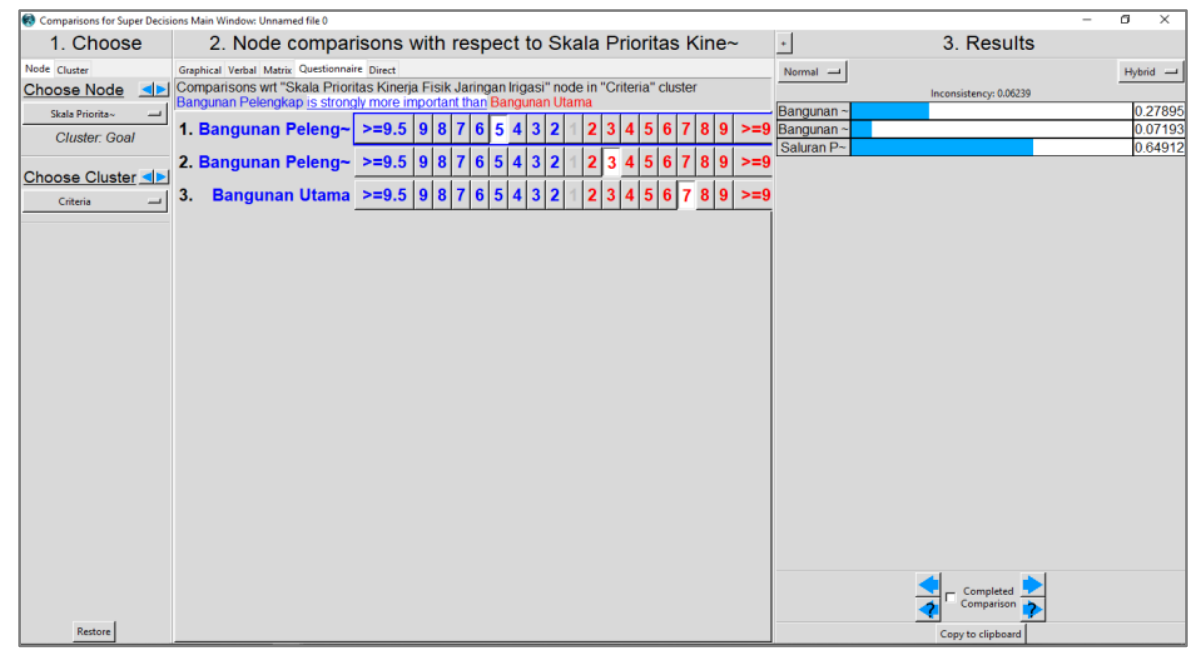

Gambar 3: Matriks Perbandingan Berpasangan Antar Kriteria dalam Program Super Decisions 2.10

Tabel 4: Matriks Perbandingan Berpasangan Antar Kriteria

\begin{tabular}{lccc}
\hline & Bangunan Utama & Saluran Pembawa & Bangunan Pelengkap \\
\hline \hline Bangunan Utama & 1 & $1 / 7$ & $1 / 3$ \\
Saluran Pembawa & 7 & 1 & 3 \\
Bangunan Pelengkap & 3 & $1 / 3$ & 1 \\
\hline
\end{tabular}

Berdasarkan hasil perhitungan matriks perbandingan didapatkan nilai vektor prioritas tiap baris. Nilai vektor prioritas lalu dihitung untuk menentukan nilai $\lambda$ maksimal, indeks konsistensi (CI), rasio indeks (RI) hingga rasio konsistensi (CR). Apabila hasil nilai CR < 0,1 artinya perbandingan matriks berpasangan konsisten atau data diterima [10]. Selanjutnya yaitu perhitungan matriks perbandingan berpasangan tiap kriteria terhadap alternatif. Pada gambar 4 dan tabel 7 adalah salah satu contoh kriteria bangunan utama terhadap alternatif.

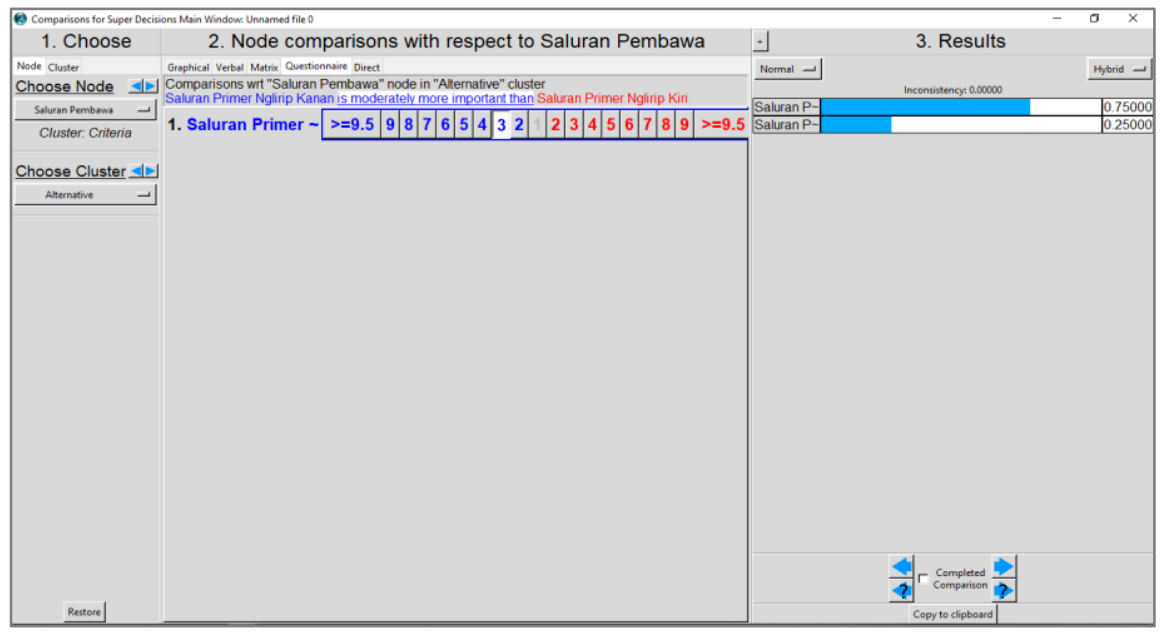

Gambar 4: Matriks Perbandingan Berpasangan Kriteria terhadap Alternatif dalam Program Super Decisions 2.10 
Tabel 4: Matriks Perbandingan Berpasangan Kriteria terhadap Alternatif

\begin{tabular}{lcc}
\hline \multicolumn{1}{c}{ Saluran Pembawa } & $\begin{array}{c}\text { Saluran Primer Nglirip } \\
\text { Kanan }\end{array}$ & $\begin{array}{c}\text { Saluran Primer Nglirip } \\
\text { Kiri }\end{array}$ \\
\hline \hline Saluran Primer Nglirip Kanan & 1 & $1 / 3$ \\
Saluran Primer Nglirip Kiri & 3 & 1 \\
\hline
\end{tabular}

Setelah semua matriks perbandingan berpasangan dihitung dan hasil CR $<0,1$, maka dapat disimpulkan semua data konsisten atau data diterima. Hal itu menunjukkan bahwa pembobotan tiap kriteria dan alternatif benar dan skala pembobotan tidak jauh [1].

\begin{tabular}{|c|c|c|c|c|}
\hline \multicolumn{5}{|c|}{ Here are the priorities. } \\
\hline Icon & Name & $\widehat{\text { Normalized by Cluster }}$ & $\longdiv { \text { Limiting } }$ & $\wedge$ \\
\hline No Icon & $\begin{array}{l}\text { Skala Prioritas Kinerja } \\
\text { Fisik Jaringan Irigasi }\end{array}$ & 0.00000 & 0.000000 & \\
\hline No Icon & Bangunan Utama & 0.08795 & 0.043973 & \\
\hline No Icon & Saluran Pembawa & 0.66942 & 0.334708 & \\
\hline No Icon & Bangunan Pelengkap & 0.24264 & 0.121318 & \\
\hline No Icon & $\begin{array}{l}\text { Saluran Primer Nglirip } \\
\text { Kanan }\end{array}$ & 0.74823 & 0.374117 & \\
\hline No Icon & $\begin{array}{l}\text { Saluran Primer Nglirip } \\
\text { Kiri }\end{array}$ & 0.25177 & 0.125883 & \\
\hline
\end{tabular}

Gambar 5: Urutan Skala Prioritas dengan Metode AHP

Berdasarkan Gambar 5 dapat dilihat bahwa urutan skala prioritas berdasarkan nilai Limiting yaitu saluran pembawa dengan nilai total 0,335 , bangunan pelengkap dengan nilai total 0,121 , dan bangunan Utama dengan nilai total 0,044 . Alternatif prioritas penanganan berdasarkan kinerja fisik yaitu Saluran Primer Nglirip Kanan dengan nilai total 0,374 lalu Saluran Primer Nglirip Kiri dengan nilai total 0,125.

\section{Kesimpulan}

Hasil penilaian kondisi fisik aset irigasi berdasarkan inventarisasi adalah bangunan utama memiliki nilai kondisi sebesar $85,08 \%$ termasuk dalam kondisi baik, saluran pembawa memiliki nilai konfisi sebesar 76,99\% termasuk dalam kondisi sedang, bangunan pelengkap memiliki nilai kondisi fisik 80,99\% termasuk dalam kondisi baik, Saluran Primer Nglirip Kanan memiliki nilai kondisi fisik 81,14\%, termasuk dalam kondisi baik, Saluran Primer Nglirip Kiri memiliki nilai kondisi fisik 79,57\%, termasuk dalam kondisi sedang. Urutan skala prioritas berdasarkan penilaian kondisi fisik yaitu saluran pembawa (nilai kondisi 76,99\%), Saluran Primer Nglirip Kiri (nilai kondisi 79,57\%), bangunan pelengkap (nilai kondisi 80,99\%), Saluran Primer Nglirip Kanan (nilai kondisi 81,14\%), bangunan utama (nilai kondisi $85,08 \%$ ). Urutan skala prioritas menggunakan metode AHP yaitu berdasarkan alternatif Saluran Primer Nglirip Kanan (nilai total 0,374), Saluran 
Primer Nglirip Kiri (nilai total 0,125). Berdasarkan kriteria Saluran pembawa (nilai total 0,335 ), bangunan pelengkap (nilai total 0,121 ), bangunan utama (nilai total 0,044 ). Skala prioritas dari kedua metode memiliki hasil yang tidak jauh berbeda, dikarenakan kedua metode menggunakan parameter penentuan prioritas yang sama.

\section{Daftar Pustaka}

[1] J. Aditya, H. Ernanda, S. Wahyuningsih, "Penerapan Manajemen Aset Irigasi Pada Daerah Irigasi Taposan", Universitas Jember, Jember, 2016.

[2] F. Afandi, M. Ismoyo, H. Prasetijo, "Penilaian Kondisi Fisik Jaringan Irigasi Sumber Nangka Kecamatan Kalisat Kabupaten Jember dengan Metode Analytical Hierarchy Process (AHP)", Universitas Brawijaya, Malang, 2012.

[3] M. Anwar, S. Sunarjono, J. Abdurrosyid, "Penerapan Analytical Hierarchy Process (AHP) dalam Penyusunan Skala Prioritas untuk Menjaga Kinerja Saluran Irigasi (Studi Kasus Saluran Induk Mataram di D.I Yogyakarta), Universitas Muhammadiyah Surakarta, Solo, 2018.

[4] Ditjen Sumber Daya Air, Kriteria Perencanaan bagian Perencanaan Jaringan Irigasi (KP-01). Jakarta: Ditjen Sumber Daya Air, 2013.

[5] Pemerintah Republik Indonesia, Peraturan Menteri Pekerjaan Umum Nomor 32/PRT/M/2007 tentang Pedoman Operasi dan Pemeliharaan Jaringan Irigasi. Jakarta: Pemerintah Republik Indonesia, 2007.

[6] Pemerintah Republik Indonesia, Peraturan Menteri Pekerjaan Umum dan Perumahan Rakyat Nomor 12/PRT/M/2015 tentang Eksploitasi dan Pemeliharaan Jaringan Irigasi. Jakarta: Kementerian Pekerjaan Umum dan Perumahan Rakyat, 2015 .

[7] Kementerian Pekerjaan Umum dan Perumahan Rakyat. (2015). Peraturan Menteri Pekerjaan Umum dan Perumahan Rakyat Nomor 14/PRT/M/2015 tentang Kriteria dan Penetapan Status Daerah Irigasi. Jakarta: Kementerian Pekerjaan Umum dan Perumahan Rakyat.

[8] Pemerintah Republik Indonesia, Peraturan Menteri Pekerjaan Umum dan Perumahan Rakyat Nomor 23/PRT/M/2015 tentang Pengelolaan Aset Irigasi. Jakarta: Kementerian Pekerjaan Umum dan Perumahan Rakyat, 2015.

[9] Y. Nugraha, S. Wahyuni, T. Prayogo, "Determinant Study for Improvement Priorities of Irrigation Assets (A Case Study of Kedungrejo Irrigation Network in Pilangkenceng Sub-district, Madiun Regency - Indonesia)", Universitas Brawijaya, Malang, 2019.

[10] A. Zamroni, R. Hadiani, Sobriyah, "Skala Prioritas Pemeliharaan dan Rehabilitasi Jaringan Irigasi Sederhana (Studi Kasus di Kabupaten Semarang)", Universitas Sebelas Maret, Surakarta, 2016. 